\title{
İskenderun Körfezi ve Samandağ (Adana-Hatay) kıyılarında gözlenen yabancı bentik foraminiferler
}

\section{Alien Benthic Foraminifers Observed on the Coasts of Gulf of iskenderun and Samandağ (Adana-Hatay)}

\author{
ENGIN MERIÇ', NIYAZI AVŞAR ${ }^{2}$, M. BAKI YOKEŞ ${ }^{3 *}$, FEYZA DINÇER ${ }^{4}$ \\ ${ }^{1}$ Moda Hüseyin Bey Sokak No: 15/4, 34710 Kadıköy, İstanbul \\ ${ }^{2}$ Çukurova Üniversitesi, Mühendislik-Mimarlık Fakültesi, Jeoloji Mühendisliği Bölümü, 01330 Balcalı-Adana \\ ${ }^{3}$ AMBRD Doğa Bilimleri, Hanımefendi Sokak No:160/6, 34384 Șișli İstanbul \\ ${ }^{4}$ Nevșehir Üniversitesi, Mühendislik ve Mimarlık Fakültesi, Jeoloji Mühendisliği Bölümü, 50300 Nevșehir
}

Geliș (received) : 17 Ağustos (August) 2018

Kabul (accepted) : 23 Kasım (November) 2018

öz

Bu çalıșma Avrupa Topluluğu'nca desteklenen, İtalyan, Türk ve İsrailli araștırmacılar tarafından İskenderun ve Hayfa körfezlerinde yürütülen "Benthic foraminifera as indicators of heavy metal pollution - A new kind of biological monitoring for the Mediterranean Sea. AVICT 92-0007" no'lu proje ile ilgili araștırmada rastlanılan yabancı foraminiferlerin bu alandaki varlığı esas alınarak hazırlanmıștır. Bunu izleyen yıllarda İskenderun Körfezi yakınlarında ve Türkiye'nin diğer kıyılarında gerçekleștirilen araștırmalarda pek çok Atlantik ve Pasifik okyanusları ile Kızıldeniz kökenli bentik foraminiferlere rastlanılmıștır.

İskenderun Körfezi çevresinde, özellikle güney doğusunda daha zengin olmak üzere Nodopthalmidium antillarum Cushman, Edentostomina cultrata (Brady), Spiroloculina cf. angulata Cushman, S. antillarum d'Orbigny, Hauerina diversa Cushman, Pseudomassilina reticulata (Heron-Allen ve Earland), Articulina alticostata Cushman, Peneroplis pertusus (Forskal), P. planatus (Fichtel ve Moll), Sorites orbiculus Ehrenberg. Pyramidulina catesbyi (d'Orbigny), Bulimina biserialis Millett, Entosigmomorphina sp., Amphistegina lobifera Larsen, Pararotalia calcariformata McCulloch, Elphidium striatopunctatum (Fichtel ve Moll), Heterostegina depressa d'Orbigny gibi yabancı bentik foraminiferlere rastlanımıștır.

Daha güneyde, Samandağ kıyı alanında ise Spiroloculina antillarum d'Orbigny, Hauerina diversa Cushman, Peneroplis arietinus (Batsch), P. pertusus (Forskal), P. planatus (Fichtel ve Moll), Sorites orbiculus Ehrenberg, Siphonina tubulosa Cushman, Cymbaloporetta plana (Cushman), Amphistegina lessonii (d'Orbigny), A. lobifera Larsen, Hansenisca soldanii (d'Orbigny), Pararotalia calcariformata McCulloch, Heterostegina depressa d'Orbigny olarak adlandırlan yabancı bentik foraminiferler bulunmuștur. Bu iki bölgede rastlanılan yabancı foraminiferler bazı noktalarda așııı derecede çoğalmıș olması ilginç bir durum olușturmaktadır. Özellikle Amphistegina lobifera Larsen ile Pararotalia calcariformata McCulloch'nın kayalar üzerinde gözlenen yoğun popülasyonları dikkate değerdir. Amphistegina lobifera Larsen'nın Doğu Akdeniz kıyılarındaki varlığı uzun zamandan beri bilinmektedir. Buna karșın Pararotalia calcariformata McCulloch yakın bir zamanda Samandağ kıyllarında gözlenmiștir. Amphistegina lobifera Larsen'e Kızıldeniz'de bol miktarda rastlanmasına karșın Pararotalia calcariformata McCulloch henüz gözlenmemiștir. Yabancı türler bölgenin ekolojik koșullarına iyi uyum sağlamıșlardır. Diğer yandan, așırı bol popülasyonların varlığı, bazı özel çevre koșullarının lokal olarak bulunduklarına ișaret etmektedir.

Anahtar Kelimeler: İskenderun Körfezi, Samandağ kıyıları, yabancı bentik foraminiferler.

\begin{abstract}
This study is based on the alien foraminifers observed during the project "Benthic foraminifera as indicators of heavy metal pollution - A new kind of biological monitoring for the Mediterranean Sea. AVICT 92-0007", which was supported by the European Union and performed by the Italian, Turkish and Israeli researchers in the Gulf of İskenderun and Hayfa Bay. In the following years, numerous Atlantic, Pacific and Red Sea originated benthic foraminifer species were recorded during the studies conducted around the Gulf of iskenderun and along the other coasts of Turkey.
\end{abstract}

* M. B. Yokeş

e-posta: bakiyokes@gmail.com 
In the Gulf of iskenderun, south coasts were found to have a more diverse foraminiferal fauna, including alien species such as Nodopthalmidium antillarum Cushman, Edentostomina cultrata (Brady), Spiroloculina cf. angulata Cushman, S. antillarum d'Orbigny, Hauerina diversa Cushman, Pseudomassilina reticulata (Heron-Allen and Earland), Articulina alticostata Cushman, Peneroplis pertusus (Forskal), P. planatus (Fichtel and Moll), Sorites orbiculus Ehrenberg. Pyramidulina catesbyi (d'Orbigny), Bulimina biserialis Millett, Entosigmomorphina sp., Amphistegina lobifera Larsen, Pararotalia calcariformata McCulloch, Elphidium striatopunctatum (Fichtel and Moll) and Heterostegina depressa d'Orbigny.

In the Samandağ coastal region, south to the Gulf of Iskenderun, alien benthic foraminifers such as Spiroloculina antillarum d'Orbigny, Hauerina diversa Cushman, Peneroplis arietinus (Batsch), P. pertusus (Forskal), P. planatus (Fichtel and Moll), Sorites orbiculus Ehrenberg, Siphonina tubulosa Cushman, Cymbaloporetta plana (Cushman), Amphistegina lessonii (d'Orbigny), A. lobifera Larsen, Hansenisca soldanii (d'Orbigny), Pararotalia calcariformata McCulloch, Heterostegina depressa d'Orbigny were found. It is interesting that the alien foraminifers recorded in these two regions show extreme abundance in certain locations. Especially, the dense populations of Amphistegina lobifera Larsen and Pararotalia calcariformata McCulloch observed on the rocky substrate is worth attention. Amphistegina lobifera Larsen has been known to be present in the Eastern Mediterranean for a long time. However, Pararotalia calcariformata McCulloch has been recently recorded on the Samandağ coasts. Amphistegina lobifera Larsen is abundant in the Red Sea, but Pararotalia calcariformata McCulloch is not observed there yet. The alien species are well adapted to the ecological conditions of the region. On the other hand, extremely abundant populations indicate some special environmental conditions locally present.

Keywords: Gulf of Iskenderun, Samandağ coasts, alien benthic foraminifers.

\section{Giriș}

İskenderun Körfezi ile Samandağ kıyı alanlarında yapılan çalıșmalarda zengin bir bentik foraminifer topluluğunun varlığı ortaya konulmuștur (Oflaz, 2012; Meriç vd., 2016a). Burada dikkati çeken durum topluluk içinde oldukça zengin denilebilecek çeșitlilikte Pasifik ve Hint okyanusları ile Kızıldeniz kökenli çeșitli bentik foraminiferlere rastlanılmıs olmasıdır.

Türkiye kıyılarında yapılan çalıșmalarda yabancı/göçmen foraminiferlerle ilgili son yıllarda bir çok çalıșma bulunmaktadır (Meriç vd., 2008; Meriç vd., 2011; Meriç vd., 2012c; Meriç vd., 2013).

Bu çalıșmada amaç, İskenderun Körfezi ile Samandağ kıyı alanlarında bulunan yabancı bentik foraminiferleri tanıtmak, Türkiye'nin diğer kıyılarında bulunan yabancı bentik foraminifer toplulukları ile karșilaștırma yapmak ve bölgeye yerleșme nedenleri hakkında yaklașımda bulunmaktır.

\section{YABANCI/GÖÇMEN FORAMINIFER BULGULARI}

İskenderun Körfezi çevresinde, Nodopthalmidium antillarum Cushman, Edentostomina cultrata (Brady), Spiroloculina cf. angulata Cushman, S. antillarum d'Orbigny, Hauerina diversa Cushman, Pseudomassilina reticulata (Heron-Allen ve Earland), Articulina alticostata Cushman, Peneroplis pertusus (Forskal), P. planatus (Fichtel ve Moll), Sorites orbiculus
Ehrenberg. Pyramidulina catesbyi (d'Orbigny), Bulimina biserialis Millett, Entosigmomorphina sp., Amphistegina lobifera Larsen, Pararotalia calcariformata McCulloch, Elphidium striatopunctatum (Fichtel ve Moll), Heterostegina depressa d'Orbigny gibi yabanCl foraminiferlere rastlanılmıștır. Bu topluluk özellikle İskenderun Körfezi'nin güneydoğusunda daha zengin olarak tespit edilmiștir (Șekil 1).

Samandağ kıyı alanında ise Spiroloculina antillarum d'Orbigny, Hauerina diversa Cushman, Peneroplis arietinus (Batsch), P. pertusus (Forskal), P. planatus (Fichtel ve Moll), Sorites orbiculus Ehrenberg, Siphonina tubulosa Cushman, Cymbaloporetta plana (Cushman), Amphistegina lessonii (d'Orbigny), A. lobifera Larsen, Hansenisca soldanii (d'Orbigny), Pararotalia calcariformata McCulloch, Heterostegina depressa d'Orbigny olarak adlandırılan yabancı bentik foraminiferler bulunmuștur (Șekil 2) (Avșar vd., 2001; Meriç vd., 2008, 2014; Oflaz, 2012).

$\mathrm{Bu}$ iki bölgede rastlanılan yabancı foraminiferlerin bazı noktalarda așıı derecede çoğalmıș olması ortaya ilginç bir durum çıkarmaktadır. İskenderun Körfezi güneyi ve Samandağ kıyı alanlarında kayalar üzerinde bulunan ve așırı bollukta gözlenen Amphistegina lobifera Larsen ile Pararotalia calcariformata McCulloch'nın bu alanlardaki varlığı dikkat çekicidir. Amphistegina lobifera Larsen'ın Doğu Akdeniz kıyılarındaki varlığı uzun zamandan beri bilinmektedir (Meriç vd., 2008). Buna karșın Pararotalia calcariformata McCulloch yakın bir zamanda Samandağ 


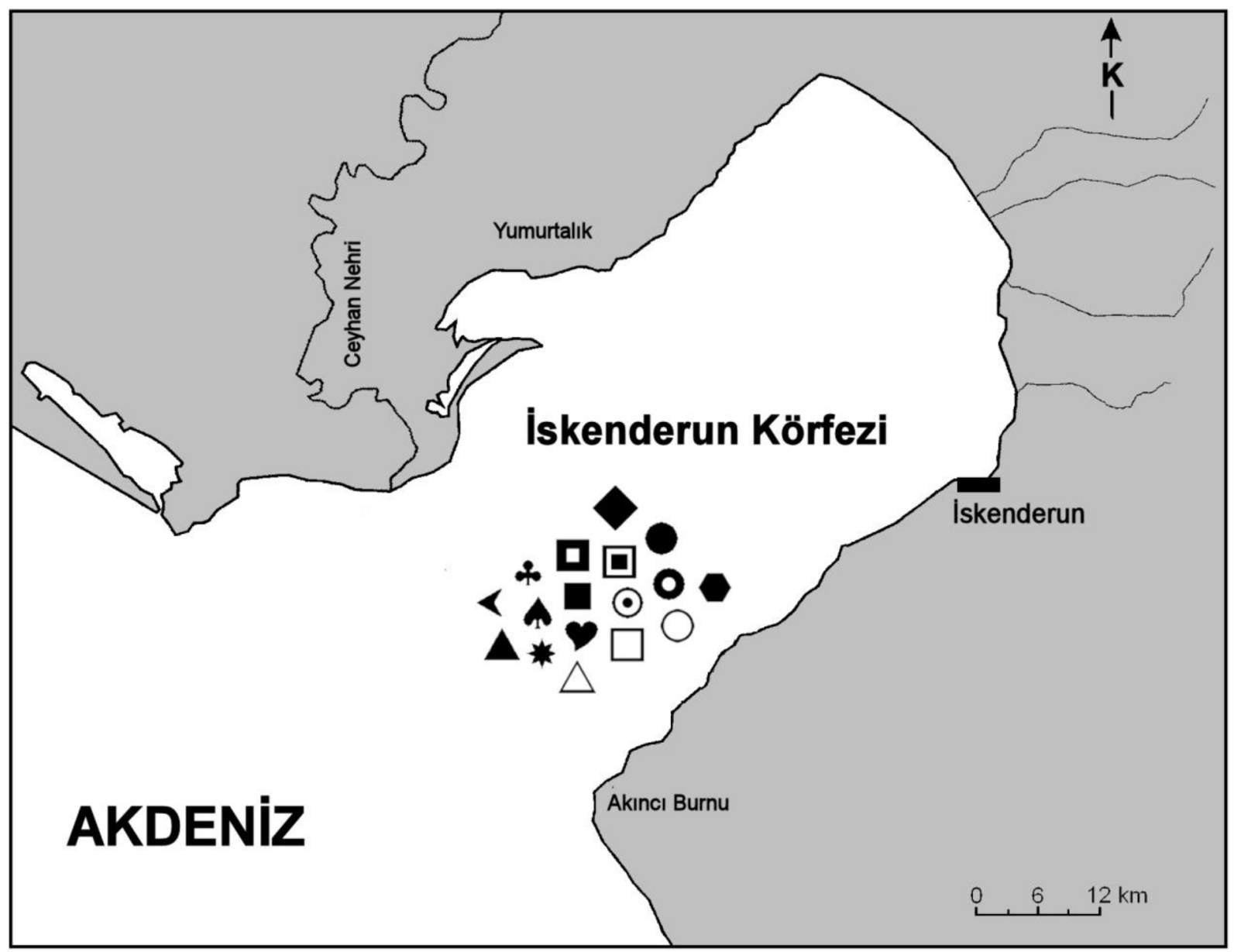

Șekil 1. İskenderun Körfezi'nde kaydedilen yabancı foraminifer türleri. ^ Nodopthalmidium antillarum Cushman, *Edentostomina cultrata (Brady), $\square$ Spiroloculina cf. S. angulata Cushman, $\diamond$ S. antillarum d'Orbigny, $\odot$ Hauerina diversa Cushman, $\bullet$ Pseudomassilina reticulata (Heron-Allen ve Earland), <Articulina alticostata Cushman, $\square$ Peneroplis pertusus (Forskal), $\square$ P. planatus (Fichtel ve Moll) $\bullet$ Sorites orbiculus Ehrenberg, $\boldsymbol{\Delta}$ Pyramidulina catesbyi (d'Orbigny), $\triangle$ Bulimina biserialis Millett, $\mathbf{\square}$ Entosigmomorphina sp., OAmphistegina lobifera Larsen, Pararotalia calcariformata McCulloch, $\square$ Elphidium striatopunctatum (Fichtel ve Moll) ve Heterostegina depressa d'Orbigny (Meriç vd., 2008'den değiștirilerek alınmıștır).

Figure 1. Alien foraminifers recorded in the Gulf of Iskenderun. ^ Nodopthalmidium antillarum Cushman, « Edentostomina cultrata (Brady), $₫$ Spiroloculina cf. S. angulata Cushman, $\diamond$ S. antillarum d'Orbigny, $\odot$ Hauerina diversa Cushman, - Pseudomassilina reticulata (Heron-Allen and Earland), <Articulina alticostata Cushman, $\square$ Peneroplis pertusus (Forskal), $\square$ P. planatus (Fichtel and Moll) • Sorites orbiculus Ehrenberg, $\boldsymbol{\Delta}$ Pyramidulina catesbyi (d'Orbigny), 口Bulimina biserialis Millett, $\mathbf{\square}$ Entosigmomorphina sp., OAmphistegina lobifera Larsen, Pararotalia calcariformata McCulloch, 口Elphidium striatopunctatum (Fichtel and Moll) ve Heterostegina depressa d'Orbigny (Modified from Meriç et al., 2008).

kıyılarında gözlenmiștir (Meriç vd., 2013, 2014). Yine Amphistegina lobifera Larsen'e Kızıldeniz'de bol miktarda rastlanmasına karșın Pararotalia calcariformata McCulloch bireyleri henüz bulunmamıștır (Meriç vd., 2013, 2014, 2016a).

\section{INDO-PASIFIK ve KIZILDENIZ KÖKENLi BENTIK FORAMINIFERLERIN GÖÇ YOLLARI}

Kızıldeniz üzerinden Akdeniz'e ulașan ve geniș alanlara yayılan yabancı bentik foraminiferler Süveyș Kanalı yolu ile Akdeniz'e girdikten sonra bașlıca yolları doğu ve batı istikameti olmak üzere etrafa yayılım gösteririler. Doğu istikametinde yayılım sunanlar 


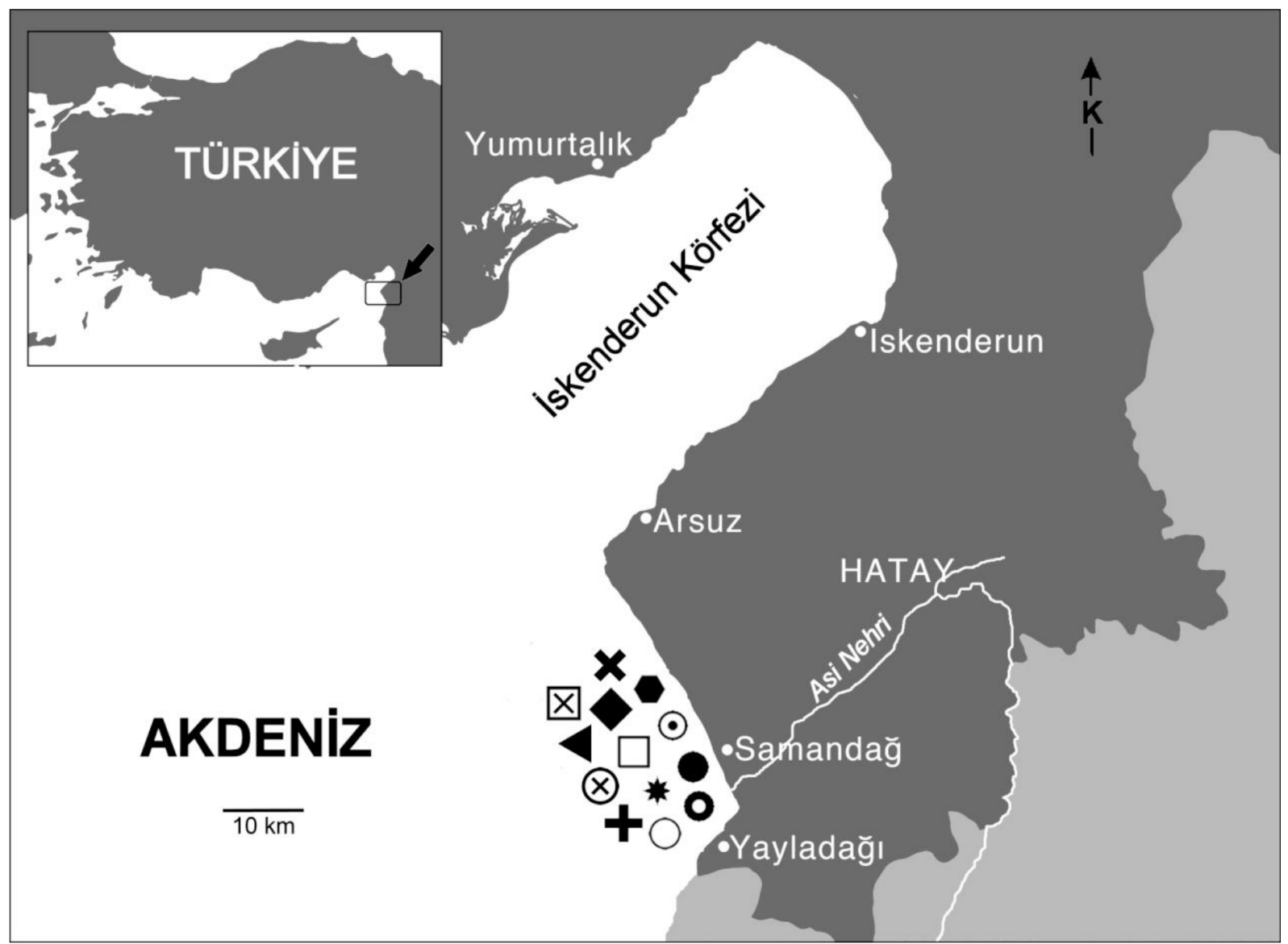

Șekil 2. Samandağ kıyılarında kaydedilen yabancı foraminifer türleri. $\diamond$ S. antillarum d'Orbigny, $\odot$ Hauerina diversa Cushman, +Peneroplis arietinus (Batsch), $\square$ P. pertusus (Forskal), $\square P$. planatus (Fichtel ve Moll) - Sorites orbiculus Ehrenberg, x Siphonina tubulosa Cushman, ®Cymbaloporetta plana (Cushman), $\triangle$ Amphistegina lessonii (d’Orbigny), OAmphistegina lobifera Larsen, 囚Hansenisca soldanii (d'Orbigny), - Pararotalia calcariformata McCulloch ve Heterostegina depressa d'Orbigny (Meriç vd., 2016a'dan değiștirilerek alınmıștır).

Figure 2. Alien foraminifers recorded on the coasts of Samandağ. $\diamond$ S. antillarum d'Orbigny, $\odot$ Hauerina diversa Cushman, +Peneroplis arietinus (Batsch), $\square$ P. pertusus (Forskal), $\square$ P. planatus (Fichtel and Moll) $\bullet$ Sorites orbiculus Ehrenberg, XSiphonina tubulosa Cushman, ®Cymbaloporetta plana (Cushman), $4 A m-$ phistegina lessonii (d’Orbigny), OAmphistegina lobifera Larsen, 凶Hansenisca soldanii (d'Orbigny), Pararotalia calcariformata McCulloch and Heterostegina depressa d'Orbigny (Modified from Meriç et al., 2016a).

kuzeydoğu Mısır, Filistin, İsrail, Lübnan ve Suriye kıyılarını takiben İskenderun Körfezi'ne ve batıya doğru yönlenerek Doğu Akdeniz'in çeșitli noktalarına ulașırlar (Șekil 3) (Meriç vd., 2015).

Bu çalıșmada değerlendirilen verilerin dıșında Silifke güneybatısında Akkuyu çevresinde yapılan bir çaıșmada, Çamalanı mevki kara alanında elde edilen çok sayıda Amphistegina lobifera Larsen bireylerinin gözlenmiș olduğu seviye 227.3ะ17.8 ka, Orta Pleyistosen olarak belirlenmiștir (Meriç vd., 2016b). Bu durumda adı geçen foraminiferin 1869 yılında açılmıș olan Süveyș Kanalı'ndan çok önce Basra KörfeziMezopotamya Havzası yolu ile Akdeniz'e ulașmıș olduğunu anlașılmıștır. Yine Süveyș Kanalı açıldıktan sonra Akdeniz'e gelmiș olduğu düșünülen Spiroloculina antillarum d'Orbigny, Articulina carinata Wiesner, Coscinospira hemprichii Ehrenberg, Peneroplis pertusus (Forskal), P. planatus (Fichtel ve Moll), Sorites orbiculus Ehrenberg, Astacolus insolitihes (Schwager), Siphonina tubulosa Cushman, Amphistegina lessonii d'Orbigny gibi yabancı bentik foraminiferlerin Geç Pleyistosen'de Akdeniz'e ulașmıș oldukları 


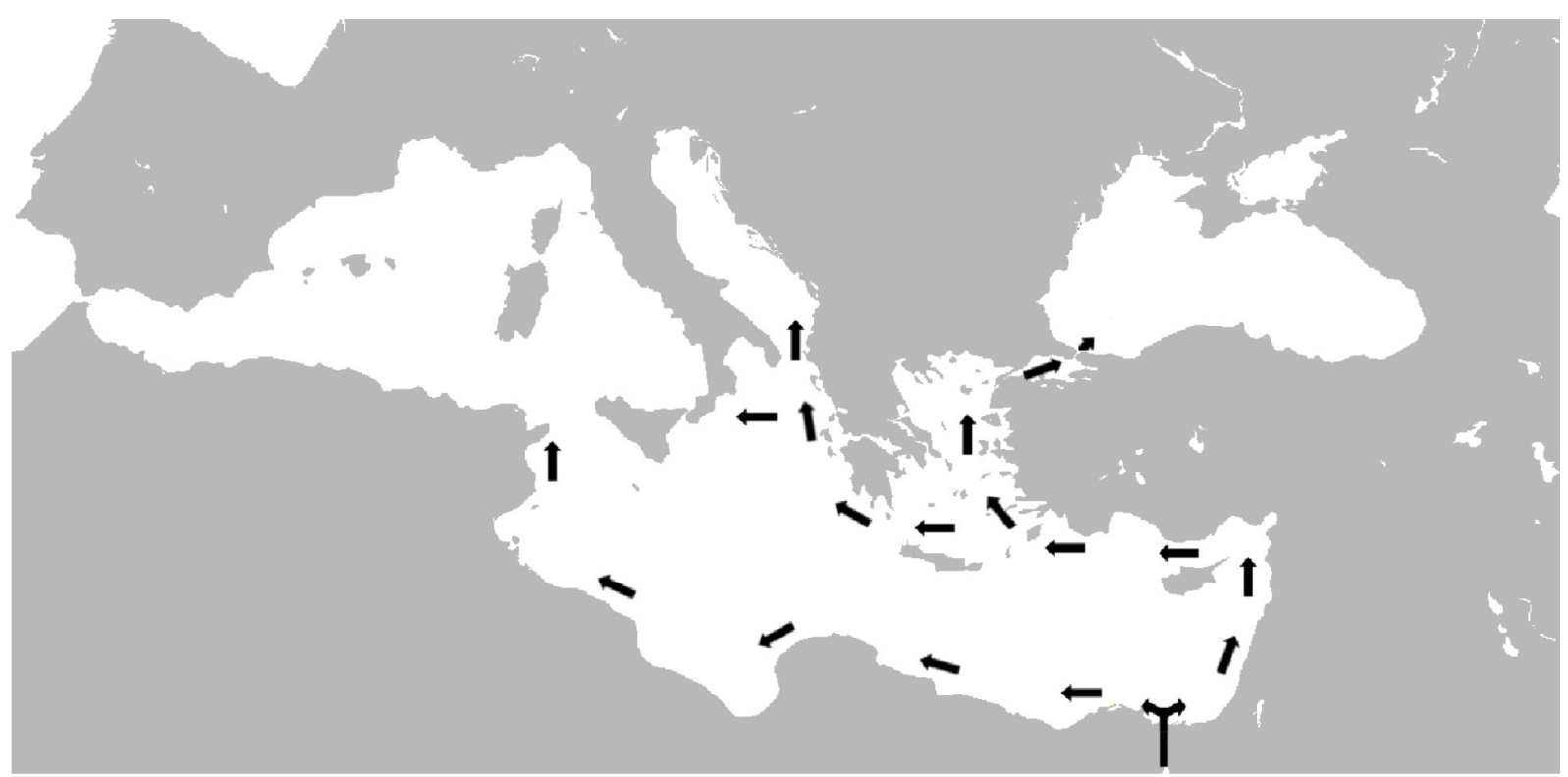

Șekil 3. Kızııdeniz kökenli yabancı bentik foraminiferlerin Doğu Akdeniz'deki dağılım yolları (Meriç vd., 2015).

Figure 3. Dispersion pathways of Red Sea originated alien benthic foraminifers in the Eastern Mediterranean (Meriç et al., 2015).

ortaya çıkmaktadır. Fakat yakın zamanda günümüzde Akdeniz'de yașamakta olan Amphistegina lobifera Larsen bireyleri ile Kızıldeniz'de yașamakta olan bireylerin DNA incelemeleri sonucunda günümüzde Akdeniz'de yașayanların Kızıldeniz kökenli olduğu ortaya konulmuștur (Schmidt vd., 2016).

\section{TARTIȘMA VE SONUÇLAR}

İskenderun Körfezi kuzeybatı ve güneydoğu alanlarında bu doğrultularda Doğu Anadolu Fay Sistemine bağı olarak çok sayıda fay bulunmaktadır (Șekil 4 ve 5). Yine bu kırık hatlarına bağlı olarak karadaki belirli noktalarda sıcak su çıktılarının varlığı da bilinmektedir. Fayların deniz içinde de devam edebileceği konusu bir gerçektir (Koral, 1995; Meriç vd., 2016c). Dolayısıyla deniz içinde de bazı sıcak noktaların olușması mümkündür ve bunların çevresinde farklı ekolojik koșullar gelișebilir. Ege Denizi deniz içi sıcak su çıktıları bu konuda en tipik örneklerdir (Meriç vd., 2008, 2010, 2011, 2012a, b ve c, 2017).

İskenderun Körfezi'nde gözlenen zengin bir foraminifer topluluğu içinde 36 ve 125 no'lu örneklerde çok sayıda yeșil, siyah, gri ve açık kahve kavkılara sahip bentik foraminiferlere rastlanılmıștır. Bunlar Vertebralina striata d'Orbigny, Adelosina partschi (d'Orbigny), A. pulchella d'Orbigny, Spiroloculina dilatata d'Orbigny, Siphonaperta aglutinans (d'Orbigny), $S$. aspera (d'Orbigny), Lachlanella variolata (d'Orbigny), Massilina secans (d'Orbigny), Quinqueloculina disparilis d'Orbigny, Q. limbata d'Orbigny, Q. stelligera Schlumberger, Triloculina marioni Schlumberger, Peneroplis pertusus (Forskal), P. planatus (Fichtel ve Moll), Sorites orbiculus Ehrenberg olarak belirlenmiștir (Yalçın vd., 2004). Gerek deniz içi ve gerekse karada ortaya çıkan termal suların çeșitli ağır metal ve eser element içerdikleri bir gerçektir. 36 no'lu örnekte Sr ile 125 no'lu örnekte Fe ve Mg fazla miktardadır. Ayrıca kavkılarda yapılan mikroprob analizlerinde $\mathrm{Cu}$, $\mathrm{Zn}$ ve $\mathrm{Pb}$ 'de saptanmıștır. Bu durum kırık hatlarına bağlı güncel hidrotermal kaynakları ișaret etmekte olup, İskenderun Körfezi doğusunda bulunan Erzin içme ve kaplıcaları bu düșünceye destek vermektedir (Șekil 5).

Bunun dıșında Hayfa (İsrail) kıyılarında tarafımızdan gerçekleștirilen bir çalıșmada çok sayıda yabancı bentik foraminifere rastlanılmıștır (Yokeș vd., yayınlanmamıs veri). Hayfa kuzeybatı ve kuzeyinden derlenmiș olan 6 örnek Nodopthalmidium antillarum (Cushman), Hauerina diversa Cushman, Pyrgo denticulata (Brady), Coscinospira acicularis (Batsch), $\mathrm{Pe}$ neroplis planatus (Fichtel ve Moll), Sorites orbiculus Ehrenberg, Epistomaroides punctatus (Said), Amphistegina lobifera Larsen, Pararotalia calcariformata McCulloch, Operculina ammoniformis (Gronovius) ve Heterostegina depressa d'Orbigny gibi çoğunlukla 


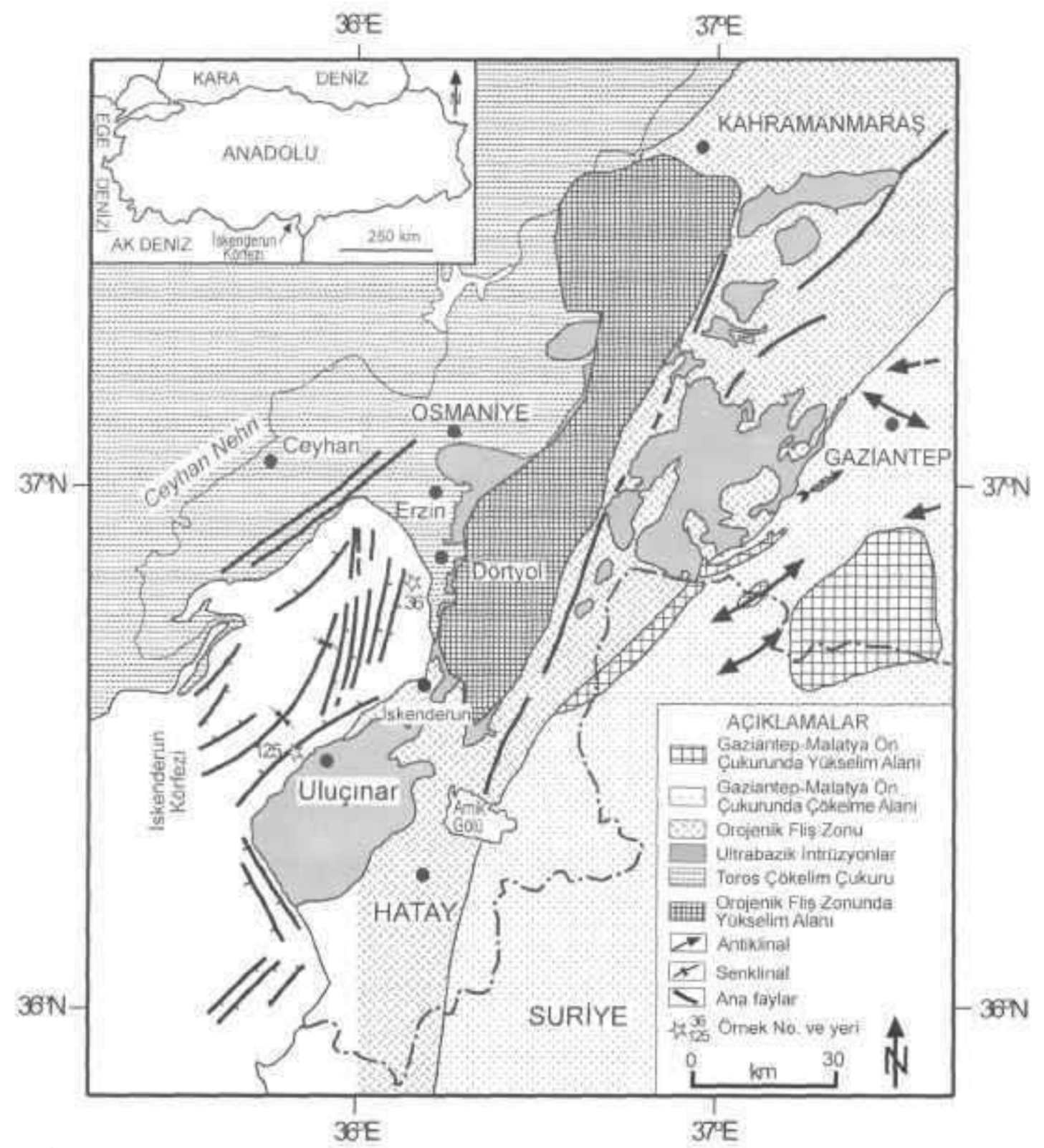

Șekil 4. İskenderun Körfezi çevresinin yapısal özellikleri ve jeoloji haritası (Koral, 1995).

Figure 4. Structural characteristics and geological map of Gulf of Iskenderun's vicinity (Koral, 1995).

Kızıldeniz kökenli olan bentik foraminiferleri içermektedir (Yokeș vd., yayınlanmamıș çalıșma).

Ayrıca Hayfa kıyılarından derlenen güncel Pararotalia calcariformata McCulloch canlı bireyleri ile ilgili olarak Bremen Üniversitesi'nde akvaryumda yetiștirilen bireyler üzerinde doktora tezi hazırlanmıștır (Schmidt, 2015). Hayfa kıyılarından derlenen örnekler üzerinde yapılan bu çalıșma Kızıldeniz kökenli birçok bentik foraminiferin yukarıda belirtildiği üzere Süveyș Kanalı'nı geçip doğu ve kuzeye yönelerek Akdeniz'de yayıım gösterdiğini kanıtlamaktadır. Pararotalia calcariformata McCulloch ise en güney nokta olarak bu alanda gözlenmiștir. Fakat Samandağ kıyılarındaki ekolojik șartların çok uygun olmasından dolayı bu alanda așırı derecede çoğalmasına neden olmuștur. Söz konusu foraminifer ilk kez Avustralya'nın güneydoğusunda Sidney güneyinde bulunmuș ve Avustralya'nın kuzey alanlarında çok az sayıda gözlenmiștir. Dolayısıyla gerek güneybatı Pasifik Okyanusu, gerek Hint okyanusu ve Kızıldeniz'de rastlanılmaması nedeniyle 


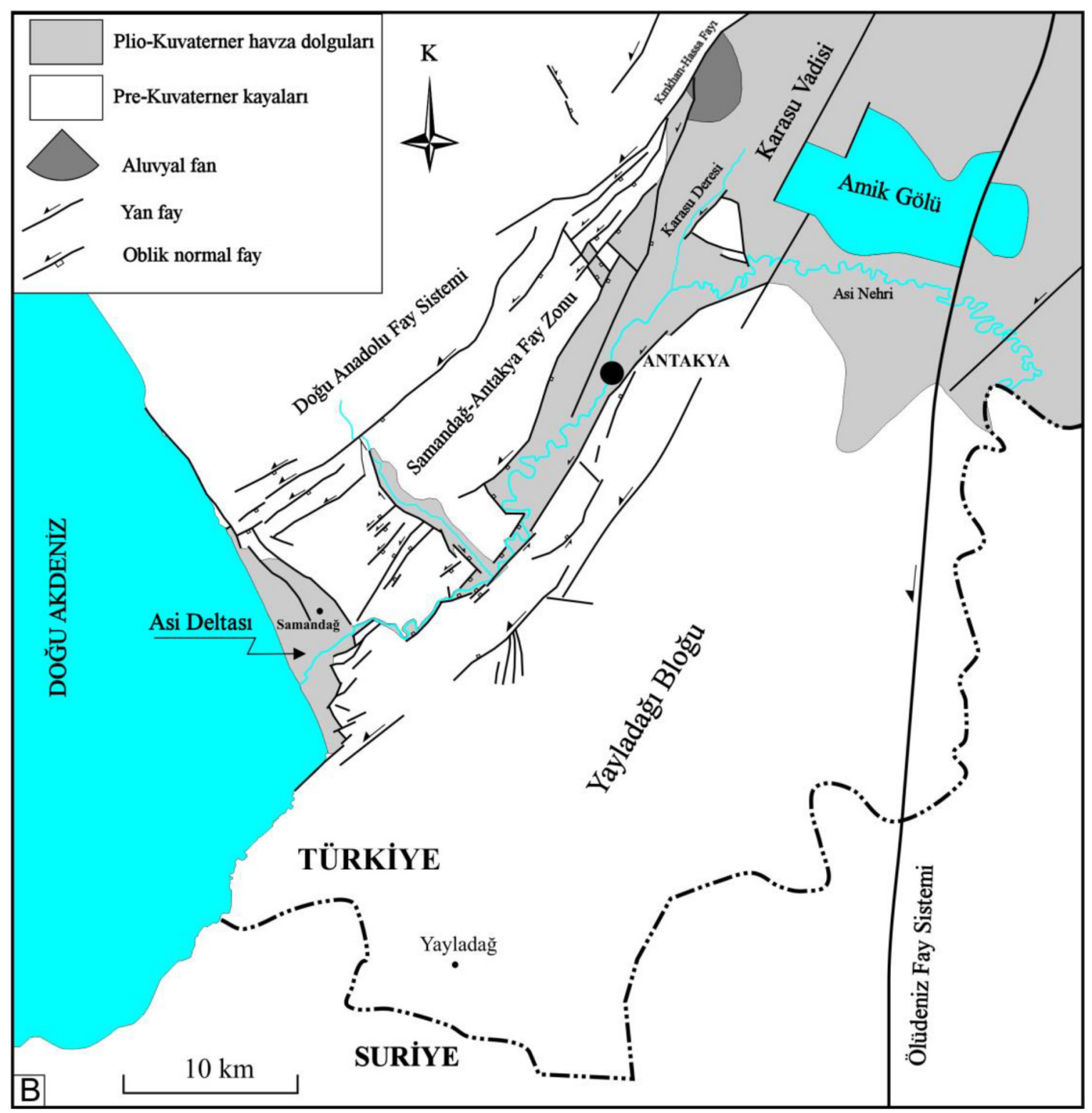

Șekil 5. Hatay çevresinde belirlenmiș olan bașlıca fay hatları (Perinçek vd., 1987, Doğan vd., 2012).

Figure 5. Main fault lines found around Hatay (Perinçek et al., 1987, Doğan et al., 2012).

Hayfa limanına gelen gemilerin balast suları ile Doğu Akdeniz'e ulașmıș olduğu ve akıntılar yoluyla kuzeye doğru yayılım gösterdiği düșünülmektedir. İskenderun Körfezi, Mersin güneydoğusu ve kuzey Ege Denizi'nde az miktarda rastlanılması aynı neden ile açıklanabilir.

Doğu Ege Denizi'nde Kușadası Koy'undaki bir sıcak su çıktısı çevresinde güney Pasifik Okyanusu kökenli Euthymonacha polita (Batsch) bireylerine bol miktarda rastlanılması ve bu foraminiferin Çeșme Ilıca Koyu ile Karaburun Yarımadası kuzeybatısında yaygın șekildeki varlığı bu tip yayılımların olduğu düșüncesine destek vermektedir (Meriç vd., 2010, 2012a, b; Yokeș vd., 2014).

Diğer bir örnek ise Çeșme llıca koyundaki (İzmir) sıcak su çıkıșları etrafında çok sayıda Coscinospira acicularis (Batsch) ile Polymorphina fistulosa (Cushman)'nın gözlenmesidir (Meriç vd., 2011, 2012a, b ve c).

Ayrıca, Doğu Ege Denizi'nin Güllük, Akköy, Ildır, Ilıca Koyu (Çeșme), Karșıyaka (İzmir Körfezi) ve Babakale (Edremit Körfezi) gibi alanlarında deniz içinde kısmen sondaj ve kepçe örnekleme (grab sampling) ile alınmıș olan örneklerde Cornuspiroides striolatus 
(Brady), Nodobaculariella cristobalensis McCulloch, N. galapagosensis McCulloch ve Pseudonodosaria brevis (d'Orbigny) gibi yabancı foraminiferler bulunmuștur (Meriç vd., 2017). Ege Denizi'nin gerek kıyı alanlarında karada ve gerekse deniz içinde var olan sıcak su kaynakları çevresinde bu gibi foraminifer cins ve türlerine rastlanmaktadır. Söz konusu foraminiferler adı geçen noktalarda yașama imkânı bulmuș ve çoğalmıșlardır.

Sonuç olarak Ege Denizi ve Doğu Akdeniz ile ilgili olarak bahsedilen tüm yabancı foraminiferlerin bu alanlarda yaygınlaștığı ve akıntılar ile güneyden kuzeye ve doğudan batıya doğru tașınan larvalarının kuzey ve batıya doğru ilerleyerek ekolojik koșulların uygun olduğu noktalarda yayılım gösterdiği ve çoğaldığı anlașılmaktadır.

\section{KAYNAKLAR}

Avșar, N., Meriç, E., Ergin, M., 2001, İskenderun Körfezi'ndeki bentojenik sedimanların foraminifer içeriği. H. Ü. Yerbilimleri, 24, 97-112, Ankara.

Doğan, U., Koçyiğit, A., Varol, B., Özer, ì., Molodkov, A., Zöhra, E., 2012. MIS $5 a$ and MIS 3 relatively high sea-level stands on the HataySamandağ Coast, Eastern Mediterranean, Turkey. Quaternary International 262: 65-79.

Koral, H., 1995, Sedimentological study: Sediments of Iskenderun Bay in the context of regional structure. In: Benthic foraminifera as indicators of heavy metal pollution - A new kind of biological monitoring for the Mediterranean Sea. AVICT 92-0007, Annual Report, 217223.

Meriç, E., Avșar, N., Yokeș, B., 2008, Some alien foraminifers along the Aegean and southwestern coasts of Turkey. Micropaleontology, in: Recent benthic foraminifera along the southwest coasts of Antalya (SW Turkey) and the impact of alien species on authocthonous fauna (eds. E.Meriç and M. B. Yokeș), 54 (3-4), 307-349.

Meriç, E., Yokeș, M.B., Avșar, N., Bircan, C., 2010, An oasis for alien benthic foraminifera in the Aegean Sea. Aquatic Invasions, 5 (2), 191195.

Meriç, E., Yokeș, B., Avșar, N., 2011, A new guest in Ilıca Bay (Çeșme-Izmir-Turkey): Coscinospira acicularis. Journal of Marine Biological Association of the United Kingdom, 4, e94, 1-5.

Meriç, E., Avșar, N., Nazik, A., Yokeș, M., Barut, I. F., Eryılmaz, M., Kam, E., Tașkın, H., Bașsarı, A., Dinçer, F., Bircan, C., Kaygun, A., 2012a, llıca Koyu (Çeșme-İzmir) bentik foraminiferostrakod toplulukları ile Pasifik Okyanusu ve Kızıldeniz kökenli göçmen foraminiferler ve anormal bireyler. M.T.A. Dergisi, 145, 62-78, Ankara.

Meriç, E., Avșar, N., Nazik, A., Yokeș, Dora, Ö., Barut, I. F., Eryılmaz, M., Dinçer, F., Kam, E., Aksu, A., Tașkın, H., Bașsarı, A., Bircan, C., Kaygun, A., 2012b, Karaburun Yarımadası kuzey kıyılarının oșinografik özelliklerinin bentik foraminifer ve ostrakod toplulukları üzerindeki etkileri. M.T.A. Dergisi, 145, 2247, Ankara.

Meriç, E., Yokeș, B., Avșar, N., Kırcı-Elmas, E., Dinçer, F., 2012c, A new record in eastern Aegean Sea (Turkey): Polymorphina fistulosa. Marine Biodiversity Records, Journal of Marine Biological Association of the United Kingdom, 5, e103, 1-3.

Meriç, E., Yokeș, M. B., Avșar, N., Kırcı-Elmas, E., Dinçer, F., Karhan, S. Ü., Kalkan, E., Demir, V., 2013. First report of Pararotalia calcariformata from the Hatay costline (Turkeynorth eastern Mediterranean). Marine Biodiveresity Records, Marine Biological Association of the United Kingdom, 6, e31, 1-4.

Meriç, E., Avșar, N., Yokeș, M. B., Dinçer, F., 2014. Atlas of recent benthic foraminifera from Turkey. Micropaleontology, 60 (3-4), 211398.

Meriç, E., Yokeș, M. B., Avșar, N., Dinçer, F., 2015. Main introduction way of Indo-Pacific and Red Sea originated benthic foraminifers to the eastern Mediterranean. International Journal of Environment and Geoinformatics, 2 (3), 07-12.

Meriç, E.,, Avșar, N., Yokeș, M. B., Dinçer, F., Karhan, S. Ü., Kalkan, E., Demir, V., 2016a. Benthic foraminiferal assemblages from the Eastarn Levantine Coast of Turkey. International Journal of Environment and Geoinformatics, 3 (2), 38-44. 
Meriç, E., Yokeș, M. B., Avșar, N., Kıyak, N. G., Öner, E., Nazik, A., Demirtașlı, E., Dinçer, F., Öztürk, M. Z., 2016b. Did Amphistegina lobifera Larsen reach the Mediterranean via the Suez Canal? Quaternary International, 401, 91-98.

Meriç, E., Öner, E., Avșar, N., Nazik, A., Güneyli, H., İslamoğlu, Y., Yokeș, M. B., Dinçer, F., 2016c. Did the Red Sea-Mediterranean connection over the Dead Sea Fault Zone end in the Late Pliocene? Quaternary International, 401, 123-131.

Meriç, E., Yokeș, M. B., Avșar, N., Yümün, Z. Ü., Dinçer, F., 2017. New alien foraminifer guests in the eastern Aegean Sea (Turkey). International Journal of Environment and Geoinformatics, 4 (3), 182-192.

Oflaz, A., 2012. Taxonomy, distribution of eastern Mediterranean benthic foraminifera. Lap Lambert Academic Publishing, 307 p.

Perinçek, D., Günay, Y., Kozlu, H., 1987. Doğu ve güneydoğu Anadolu yöresindeki yanal atımlı faylar ile ilgili yeni gözlemler. Türkiye 7 . Petrol Kongresi, Bildiriler-Jeoloji, 89-103, 6-10 Nisan 1987, Ankara.
Schmidt, C., 2015. Global change stress on symbiont: Bearing benthic foraminifera. Doktorgrades in den Naturwissenschaften (Dr. rer. Nat.). Universitat Bremen, $162 \mathrm{p}$.

Schmidt, C., Morard, R., Prazeres. M., Barak, H., Kucera, M., 2016. Retention of high thermal tolerance in the invasive foraminifera Amphistegina lobifera from the eastern Mediterranean and the Gulf of Aqaba. Marine Biology, 163, 228.

Yalçın, H., Meriç, E., Avșar, N., Bozkaya, Ö., Barut, i. F., 2004. İskenderun Körfezi güncel foraminiferlerinde gözlenen jeokimyasal anomaliler. Türkiye Jeoloji Bülteni, 47 (2), 25-39, Ankara.

Yokeș, M. B., Meriç, E., Avșar, N., Barut, I. F., Taș, S., Eryılmaz, M., Dinçer, F., Bircan, C., 2014, Opinion and comments on the benthic foraminiferal assemblages observed around the mineral submarine springs in Kușadası (Aydın-Turkey). Marine Biological Association of the United Kingdom, 1-17, doi:10.1017/ S1755267214000840, vol. 7, e103; 2014, published on line. 
